\title{
Redes de apoyo a las familias griegas con hijos discapacitados en edad escolar
}

\author{
Assimina Tsibidaki, Anastasia Tsamparli
}

Departamento de Educación Primaria, Universidad del Egeo, Rodas

\section{Grecia}

tsimpidaki@rhodes.aegean.gr 


\section{Resumen}

Introducción. La interacción de la familia con hijos discapacitados con las redes de apoyo es una area de investigación de gran actualidad (Hendriks, De Moor, Oud y Savelberg, 2000). Se ha demostrado que las redes de apoyo pueden resultar de mucha ayuda para la familia, y, sobre todo, para las familias con hijos discapacitados. Las redes de apoyo juegan un papel primordial en el esfuerzo familiar para adaptarse a la discapacidad, y responder a las necesidades psicosociales de los familiares (DeMarle y Le Roux, 2001). El objetivo de esta investigación es representar las redes de apoyo y el grado de satisfacción con este apoyo, tal como lo experimentan 30 familias griegas que tienen hijos en edad escolar, y después comparar esta experiencia con la de 30 familias con hijos no discapacitados.

Método. La muestra consiste en 60 familias nucleares, en total, 120 padres de estatus socioeconómico medio, todos con residencia permanente en la isla de Rodas, Grecia. La recogida de datos utilizó: 1) el Genogram (Bowen, 1978), 2) el Family's Ecomap [eco-mapa de la familia] (Hartman, 1978a), 3) el Social Support Questionnaire [cuestionario sobre el apoyo social] (Sarason, Sarason, Sherin y Pierce, 1987), y 4) entrevistas semi-estructuradas.

Resultados. Según los hallazgos del estudio, las familias, con o sin hijos discapacitados, comparten redes de apoyo comunes (familia de origen, amigos, religión), pero las familias con un hijo discapacitado también utilizan otras redes de apoyo (otras familias con hijos discapacitados, especialistas,...). Todas las familias expresan su satisfacción cuando se refieren a las redes de apoyo compuestas de individuos. El grado de satisfacción es irregular cuando se refiere a las redes de apoyo institucionalizadas.

Conclusión. Las familias con hijos discapacitados no se sienten apoyadas adecuadamente por las estructuras sociales (escuela, centros de intervención,...). Esto se debe al hecho de que las regiones remotas de Grecia carecen de estructuras de apoyo a estas familias. Además, las familias sienten ansiedad e ira a causa de esta carencia de apoyo social (servicios, personal especializado, prácticas discriminatorias, etc.).

Palabras clave: Redes de apoyo, discapacidad, familia, satisfacción

$\begin{array}{ll}\text { Recepción del artículo: } & 03-09-2007 \\ \text { Aceptación provisional: } & 28-06-2007 \\ \text { Aceptación definitiva: } & 15-08-2007\end{array}$

